\title{
Patient and general population values for luminal and perianal fistulising Crohn's disease health states
}

\author{
Fanni Rencz ${ }^{1,2}$ (1) Peep F. M. Stalmeier ${ }^{3} \cdot$ Márta Péntek $^{1}$ (1) $\cdot$ Valentin Brodszky ${ }^{1}$ (1) - Gábor Ruzsa ${ }^{4,5}$ (1)

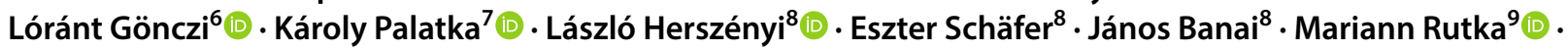 \\ László Gulácsi ${ }^{1}$ (1) Peter L. Lakatos ${ }^{6,10}$
}

Received: 5 March 2019 / Accepted: 13 April 2019 / Published online: 17 May 2019

(c) The Author(s) 2019

\begin{abstract}
Background In patients with Crohn's disease (CD), luminal disease activity paralleled by perianal fistulas may seriously impair health-related quality of life (HRQoL). Health utility values are not available from patients with $\mathrm{CD}$ that reflect the health loss associated with both luminal and perianal CD.

Objective To generate utilities for luminal and concomitant perianal fistulising CD health states directly from patients and from members of the general public.

Methods A cross-sectional survey was undertaken enrolling CD patients and a convenience sample of members of the general population. Respondents were asked to evaluate four common CD heath states [severe luminal disease (sCD), mild luminal disease ( $\mathrm{mCD}$ ), severe luminal disease with active perianal fistulas (sPFCD), and mild luminal disease with active perianal fistulas (mPFCD)] by 10-year time trade-off (TTO). In addition, patients assessed their current HRQoL by the TTO method. Results Responses of 206 patients (40.8\% with perianal fistulas) and 221 members of the general population were analysed. Mean \pm SD utilities among patients for $\mathrm{SPFCD}, \mathrm{sCD}, \mathrm{mPFCD}$ and $\mathrm{mCD}$ states were $0.69 \pm 0.33,0.73 \pm 0.31,0.80 \pm 0.29$ and $0.87 \pm 0.26$. Corresponding values in the general public were: $0.59 \pm 0.31,0.65 \pm 0.29,0.80 \pm 0.26$ and $0.88 \pm 0.25$. Patients with active perianal fistulas, previous non-resection surgeries, and higher pain intensity scores valued their current health as worse $(p<0.05)$.

Conclusions TTO is a feasible method to assess HRQoL in patients with perianal fistulising disease, often not captured by health status questionnaires. Utilities from this study are intended to support the optimization of treatment-related decision making in patients with luminal disease paralleled by active perianal fistulas.
\end{abstract}

Keywords Crohn's disease · Perianal fistula $\cdot$ Quality of life · Time trade-off · Utility · QALY · Hungary

JEL Classification I10

László Gulácsi and Peter L. Lakatos have equally contributed to this work.

Electronic supplementary material The online version of this article (https://doi.org/10.1007/s10198-019-01065-y) contains supplementary material, which is available to authorized users.

Fanni Rencz

fanni.rencz@uni-corvinus.hu

Extended author information available on the last page of the article

\section{Introduction}

Crohn's disease (CD) is a chronic inflammatory disorder of the gastrointestinal tract, often characterised by potentially debilitating symptoms such as abdominal pain, rectal bleeding, diarrhoea, fatigue and urgency [1]. Perianal fistulising Crohn's disease (PFCD) is a common manifestation of CD affecting up to $40 \%$ of all patients [2]. In the majority of cases, perianal disease is paralleled by luminal disease activity. Symptoms of PFCD include pain, scarring, discharge, faecal incontinence and sexual difficulties. In addition to physical symptoms associated with $\mathrm{CD}$, there may be adverse psychosocial effects [3, 4]. The resulting 
morbidity may seriously compromise health-related quality of life (HRQoL) and employment status of patients [5-7]. Despite the large burden of disease, HRQoL in PFCD has been less documented compared to luminal CD [8-10].

Few HRQoL studies have elicited health utilities for CD health states using a direct method [11]. Utilities are values measured on a cardinal scale anchored on $0(=$ death $)$ and 1 (=full health), which measure the impact of an illness on HRQoL $[12,13]$. These utilities are required in cost-effectiveness analyses to calculate health benefits of a treatment expressed as quality-adjusted life years (QALYs). In the past 2 decades, biological drugs revolutionised the treatment of both luminal and fistulising CD [14, 15]; nevertheless, no reliable directly elicited health utilities are present for the cost-effectiveness analyses of biological drugs $[16,17]$.

Utility studies in CD were mostly conducted about 2 decades ago before or in the early era of biological drugs [18-20], often had a low sample size ( $<50$ patients) [18, $20,21]$, concerned only luminal disease but not PFCD [19, 20], or suffered from a number of methodological shortcomings [21]. A very recent study from the UK used both patients and a general population sample to derive utilities for various PFCD health states [22]. In this study, luminal disease severity was constant for all health states, and the study focused on surgical outcomes of perianal fistulas. The utilities elicited may be less useful for cost-effectiveness models of biological drugs that are indicated to be effective for treating both luminal and PFCD. Therefore, utilities reflecting the health loss associated with luminal and concomitant perianal disease are needed.

The present study was designed to (1) generate utilities for common $\mathrm{CD}$ health states featuring luminal or luminal and concomitant perianal disease from the perspective of patients and members of the general public; (2) compare utilities for luminal CD to those when parallel perianal symptoms are present; (3) explore the impact of perspectives on health utilities, and (4) determine whether utilities are related to respondents' demographics, health status or clinical characteristics.

\section{Methods}

\section{Study design}

Two cross-sectional surveys were undertaken. First, a paperbased survey was conducted with patients diagnosed with $\mathrm{CD}$ regardless of having perianal fistulising disease. The second, Internet-based, survey included members of the general population. Permission for conducting the study was granted by the National Scientific and Ethical Committee (Reference no. 49548-4/2016/EKU). An informed consent form was signed by all participants.

\section{Data collection: patient survey}

Data were collected between October 2016 and September 2017. Consecutive outpatients over 18 years from three academic gastroenterology departments and an inflammatory bowel diseases (IBD) centre in Hungary were enrolled in the study. The survey comprised of a paper-based questionnaire, the first part of which was completed by the patients, and the second by their gastroenterologist. Patients were asked about their socio-demographic characteristics and health status. CD-related pain intensity was recorded on a horizontal visual analogue scale (VAS) with the endpoints of 'no pain at all' $(=0)$ and 'pain as bad as it could be' $(=10)$.

In the second part of the survey, gastroenterologists provided data about the medical history, clinical characteristics and treatments of their patients. Gastroenterologists assessed disease severity using Crohn's Disease Activity Index (CDAI) and Perianal Disease Activity Index (PDAI) [23, 24]. The CDAI is primarily based on a list of clinical symptoms or laboratory findings in the past 7 days. CDAI total scores range from 0 to 600 , where a higher score represents a more severe disease. The PDAI includes five items (i.e., discharge, pain/restriction of activities, restriction of sexual activity, type of perianal disease and degree of induration). Total PDAI score varies between 0 and 20, where a score of $\leq 4$ identifies an inactive disease, whereas a PDAI of $>4$ suggests an active fistulising disease [24, 25].

\section{Data collection: general population survey}

Internet-based questionnaires were completed between November 2017 and March 2018. A convenience sample of the general population (aged $\geq 18$ years) was recruited from the campus of Corvinus University of Budapest to participate in the survey. Participation was voluntary, anonymous and no remuneration was offered. The questionnaire collected data on socio-demographic characteristics of the respondents as well as their prior knowledge about $\mathrm{CD}$ (e.g., have known someone with $\mathrm{CD}$ ). All questions of the online survey were mandatory, so respondents could not proceed to the next question without answering the previous one.

\section{Utility assessment}

\section{Health state vignettes}

Four health state vignettes were designed: severe luminal disease ( $\mathrm{SCD}$ ), mild luminal disease (mCD), severe luminal disease with active perianal fistulas (sPFCD), and mild luminal disease with active perianal fistulas (mPFCD). The descriptions were developed by a group of IBD experts and health economists experienced in utility assessment. The final vignettes combined a description of living with 
CD including intestinal symptoms, abdominal pain, fistula symptoms, sleep, extraintestinal symptoms, eating, work/ school, and leisure and social activities (Supplementary material S1). The descriptions were presented from a firstperson perspective in a table format, as an earlier study reported that patients strongly prefer this format over narrative health state descriptions [26]. Subjects were asked to read the descriptions carefully and imagine living in the condition described.

\section{Time trade-off (TTO)}

All TTO tasks were self-administered. The TTO method elicits HRQoL or utility values for imperfect health states by asking respondents to make a trade off between quality and length of life [13]. We opted to use a 10-year time frame, as this is most commonly used for the valuation of health states [27-32]. Individuals were asked to imagine living in the CD health states as described in the vignettes for the ensuing 10 years, followed by death. Then they had to indicate how many life years they would give up to regain full health. Respondents were offered to choose from 20 predefined, tradable amounts of time ( 0 years, 6 months, 1 year,..., 9 years, 9.5 years and 10 years). An example for a TTO valuation task is provided in Supplementary material S2. The four health states were randomized within respondents both for patients and the general population sample.

TTO utilities were calculated according to the following formula:

Utility $=1-$ disutility $=1-\frac{\text { participant's answer }}{10 \text { years }}$.

Suppose, for example, a respondent indicated to exchange 2 years, yielding $U=(10-2) / 10=0.8$. Therefore, TTO utilities in this study were anchored on 0 (death) and 1 (full health).

\section{Statistical analyses}

Socio-demographic and clinical characteristics of the patient and general population groups were compared using a Student's $t$ test and $\chi^{2}$ test. All non-missing TTO responses were included in the primary data analysis. Descriptive statistics (mean, median, standard deviation and IQR) of utilities were computed. A paired $t$ test was used to test the difference between TTO utilities for hypothetical health states. TTO utilities within subgroups of patients were compared by Student's $t$ test or analysis of variance (ANOVA), where applicable.

We performed random-effects linear regression models to explore demographic, clinical and other possible predictors of utilities for hypothetical health states. Before running the models, the following participants were excluded: (1) non-traders (i.e., who valued all health states equal to full health), (2) who indicated the same value for all health states, (3) who had more than two missing TTO responses out of the four hypothetical health states and (4) who indicated a logical inconsistency (i.e., utilities for $\mathrm{sCD}>\mathrm{mCD}$ or $\mathrm{sPFCD}>\mathrm{mPFCD}$ or $\mathrm{sPFCD}>\mathrm{mCD}$ ). Determinants of utilities for current health were analysed by ordinary least squares regression. No exclusions were applied before the regression analysis of utilities for current health. All the statistics were two-sided, and $p<0.05$ was considered statistically significant. Data were analysed using Stata 13 (College Station, TX, USA: StataCorp LP).

\section{Results}

\section{Demographic and clinical characteristics of the study populations}

Overall, 206 patients with CD and 221 adults from the general population participated in the study. There were a total of $41(4.0 \%)$ missing TTO responses from patients: $n=7$ for $\mathrm{sCD}, n=7$ for $\mathrm{mCD}, n=9$ for $\mathrm{sPFCD}, n=13$ for $\mathrm{mPFCD}$ and $n=5$ for current health. There were no missing responses in the general population sample.

Table 1 provides demographic characteristics of the study participants. Patients and members of the general population were similar with respect to demographics. Patients were on average 3 years younger compared to the general population. There was a slight male predominance in both groups. A total of $28.8 \%$ of patients had a tertiary education, while this rate was $56.1 \%$ for the general population sample. The distribution of participants in the two groups was more or less balanced according to employment status and place of residence within the country.

More than two-thirds of the general population sample have never heard about CD. Altogether, $16.7 \%$ have read or heard about $\mathrm{CD}$ from the internet/media/newspapers, $8.6 \%$ learned about $\mathrm{CD}$ as they were being employed in healthcare, $4.1 \%$ had a family member or acquaintance suffering from $\mathrm{CD}$ and $3.6 \%$ indicated to be diagnosed with CD (Table 1).

Table 2 presents the clinical characteristics of the patient sample. Mean \pm SD disease duration was $10.5 \pm 6.3$ years. Eighty-four patients $(41 \%)$ had perianal fistulas, $36.1 \%$ of them being active. Extraintestinal manifestations were present in 57 patients $(27.7 \%)$. At the time of the survey, $66 \%$ received biological therapy (infliximab $47.6 \%$, adalimumab $17.5 \%$ and vedolizumab $1.9 \%$ ). 
Table 1 Demographics and general health in the study populations

\begin{tabular}{|c|c|c|c|}
\hline \multirow[t]{2}{*}{ Variables } & \multicolumn{2}{|c|}{ Mean $(\mathrm{SD})$ or $N(\%)$} & \multirow[t]{2}{*}{$p$ value } \\
\hline & $\begin{array}{l}\text { Patients with CD } \\
(n=206)\end{array}$ & $\begin{array}{l}\text { General population sample } \\
(n=221)\end{array}$ & \\
\hline \multicolumn{4}{|l|}{ Sex } \\
\hline Female & $93(45.1 \%)$ & $71(32.1 \%)$ & \multirow[t]{2}{*}{$<0.001$} \\
\hline Male & $113(54.9 \%)$ & $150(67.9 \%)$ & \\
\hline Age (years) & $34.7(10.5)$ & $37.3(15.5)$ & $<0.001$ \\
\hline \multicolumn{4}{|l|}{ Age groups (years) } \\
\hline $18-24$ & $37(18.0 \%)$ & $75(33.9 \%)$ & \multirow[t]{4}{*}{$<0.001$} \\
\hline $25-34$ & $71(34.5 \%)$ & $39(17.6 \%)$ & \\
\hline $35-44$ & $59(28.6 \%)$ & $27(12.2 \%)$ & \\
\hline$\geq 45$ & $39(18.9 \%)$ & $80(36.2 \%)$ & \\
\hline \multicolumn{4}{|l|}{ Education $(n=1)$} \\
\hline Primary school & $14(6.8 \%)$ & $4(1.8 \%)$ & \multirow[t]{3}{*}{$<0.001$} \\
\hline Secondary school & $132(71.2 \%)$ & $93(42.1 \%)$ & \\
\hline College/university & $59(28.8 \%)$ & $124(56.1 \%)$ & \\
\hline \multicolumn{4}{|l|}{ Employment } \\
\hline Student & $25(12.1 \%)$ & $63(28.5 \%)$ & $<0.001$ \\
\hline Full time & $110(53.4 \%)$ & $100(45.2 \%)$ & 0.092 \\
\hline Part time & $30(14.6 \%)$ & $21(9.5 \%)$ & 0.107 \\
\hline Unemployed & $11(5.3 \%)$ & $9(4.1 \%)$ & 0.536 \\
\hline Retired & $3(1.5 \%)$ & $12(5.4 \%)$ & 0.026 \\
\hline Disability pensioner & $49(23.8 \%)$ & $4(1.8 \%)$ & $<0.001$ \\
\hline Other & $15(7.3 \%)$ & $12(5.4 \%)$ & 0.424 \\
\hline \multicolumn{4}{|l|}{ Place of residence } \\
\hline Capital (Budapest) & $45(21.8 \%)$ & $102(46.2 \%)$ & $<0.001$ \\
\hline County town & $34(16.5 \%)$ & $24(10.9 \%)$ & 0.089 \\
\hline Smaller town & $81(39.3 \%)$ & $63(28.5 \%)$ & 0.018 \\
\hline Village & $46(22.3 \%)$ & $32(14.5 \%)$ & 0.036 \\
\hline Subjective life expectancy (years) & $76.3(12.4)$ & $79.0(11.0)$ & 0.019 \\
\hline \multicolumn{4}{|c|}{ Prior experiences with $\mathrm{CD}$ of participants from the general population } \\
\hline Have never heard about it & N/A & $153(69.2 \%)$ & N/A \\
\hline Have heard about it ${ }^{\mathrm{a}}$ & N/A & $68(30.8 \%)$ & N/A \\
\hline Have been diagnosed with $\mathrm{CD}$ & N/A & $8(3.6 \%)$ & N/A \\
\hline Have a family member or acquaintance with $\mathrm{CD}$ & N/A & $9(4.1 \%)$ & N/A \\
\hline Doctor & N/A & $9(4.1 \%)$ & N/A \\
\hline Employed in healthcare (but not a doctor) & N/A & $10(4.5 \%)$ & N/A \\
\hline Medical student & N/A & $1(0.5 \%)$ & N/A \\
\hline Read/heard about it from the Internet/media/newspaper & N/A & $37(16.7 \%)$ & N/A \\
\hline Other & N/A & $5(2.3 \%)$ & N/A \\
\hline
\end{tabular}

${ }^{a}$ One person may have heard about it from multiple sources

$C D$ Crohn's disease, N/A not applicable

\section{Utility results}

Table 3 shows the mean utilities derived from the two groups for the hypothetical health states as well as current health for patients. Among patients, mean utilities were $0.69 \pm 0.33$ for $\mathrm{SPFCD}, 0.73 \pm 0.31$ for $\mathrm{SCD}, 0.80 \pm 0.29$ for $\mathrm{mPFCD}$ and $0.87 \pm 0.26$ for $\mathrm{mCD}$ health state. Corresponding values in the general public were as follows: $0.59 \pm 0.31,0.65 \pm 0.29$, $0.80 \pm 0.26$ and $0.88 \pm 0.25$. In both groups, significant differences were observed across all hypothetical health states $(p<0.001)$.

For each health state, the proportion of patients not willing to give up any time (i.e., ' 1 ' answers) is presented in Table 3. Among patients, this rate ranged from $27.9 \%$ for 
Table 2 Clinical characteristics of CD patients $(n=206)$

\begin{tabular}{lc}
\hline & Mean (SD) or $N(\%)$ \\
\hline Body mass index, BMI $\left(\mathrm{kg} / \mathrm{m}^{2}\right)($ missing $n=2)$ & $23.4(4.3)$ \\
Underweight $(\mathrm{BMI}>18.5)$ & $22(10.8 \%)$ \\
Normal (BMI 18.5-24.9) & $111(54.4 \%)$ \\
Overweight (BMI 25.0-29.9) & $57(27.9 \%)$ \\
Obesity (BMI >30) & $14(6.9 \%)$ \\
Extraintestinal manifestations & $57(27.7 \%)$ \\
Disease severity: CDAI $(0-600)$ & $110.5(77.0)$ \\
Symptomatic remission $(\mathrm{CDAI}<150)$ & $156(75.7 \%)$ \\
Mild (CDAI 150-219) & $32(15.5 \%)$ \\
Moderate to severe $(\mathrm{CDAI} 220 \leq)$ & $18(8.7 \%)$ \\
Perianal fistula severity: PDAI $(0-20)($ missing $n=1)$ & $3.68(2.29)$ \\
Inactive (PDAI $\leq 4)$ & $53(63.9 \%)$ \\
Active (PDAI $>4)$ & $30(36.1 \%)$ \\
Pain & \\
Pain VAS (0-100) & $24.7(23.9)$ \\
Current treatment & \\
None & $3(1.5 \%)$ \\
Systemic non-biological & $67(32.5 \%)$ \\
Biological & $136(66.0 \%)$ \\
Previous surgeries due to CD & \\
None & $86(42.2 \%)$ \\
Resection surgery & $66(32.0 \%)$ \\
Non-resection surgery ${ }^{\mathrm{b}}$ & $86(41.7 \%)$ \\
\hline Bin & \\
\hline
\end{tabular}

$B M I$ body mass index, $C D$ Crohn's disease, CDAI Crohn's Disease Activity Index, PDAI Perianal Disease Activity Index, $V A S$ visual analogue scale

${ }^{a}$ Overall, 33 patients had both resection and non-resection surgeries

${ }^{\mathrm{b}}$ Perianal fistula surgery, strictureplasty or abscess drainage
sPFCD to $58.3 \%$ for $\mathrm{mCD}$. In contrast, these figures were $9.0 \%$ and $55.9 \%$ for the general public. There were 50 patients $(24.3 \%)$ and 26 members of the general population $(11.8 \%)$ who were non-traders (i.e., rated all health states equal to ' 1 ', including their current health for patients). Overall, $4.1 \%, 2.0 \%, 2.6 \%$ and $1.5 \%$ rated the $\mathrm{SPFCD}, \mathrm{sCD}$, $\mathrm{mPFCD}$ and $\mathrm{mCD}$ to be as bad as dead (utility $=0$ ).

Mean TTO utilities from patients were higher for the two severe health states compared to the general public $(p<0.01)$. There was no statistically significant difference in TTO scores for the two mild health states between the two groups.

Table 4 demonstrates the mean current health state utility for subgroups of patients. Mean utility for patients' current health was $0.83 \pm 0.28$. The TTO method well discriminated between patients with active perianal fistulas and those with inactive or no fistulas $(0.67 \pm 0.37$ vs. $0.86 \pm 0.26 ; p=0.013)$. Previous non-resection $(0.76 \pm 0.33)$ or both resection and non-resection $(0.75 \pm 0.37)$ surgeries were associated with lower mean TTO values $(p=0.023)$. Differences between groups based on CDAI score also showed a trend towards statistical significance.

\section{Multivariate analysis of predictors of utilities}

Supplementary material S3 demonstrates the results of regression models about predictors of TTO utilities. Patients' utilities for the hypothetical health states were decreased by 0.012 with 1-point increase in body mass index (BMI) $(p=0.005)$. One-point increase in disease severity on CDAI resulted in a 0.001 decrease in utilities $(p=0.036)$. Employment status of patients had a significant impact on utilities, those working full time indicated lower values by $0.071(p=0.020)$.

With respect to patients' current health, each 1-point increase in pain intensity on a VAS (scale range $0-10$ ) was associated with a 0.032 decrease in TTO utilities $(p<0.001)$. Patients who previously had a non-resection surgery due to $C D$ rated hypothetical health states to 0.095 lower $(p=0.015)$. Patients who were retired valued their current health utility lower by 0.176 , while those who were students gave higher values by, on average, 0.106 .

Among members of the general public, TTO values for hypothetical health states increased by 0.002 with every 1 -year increase in age and by 0.003 with every 1 -year 


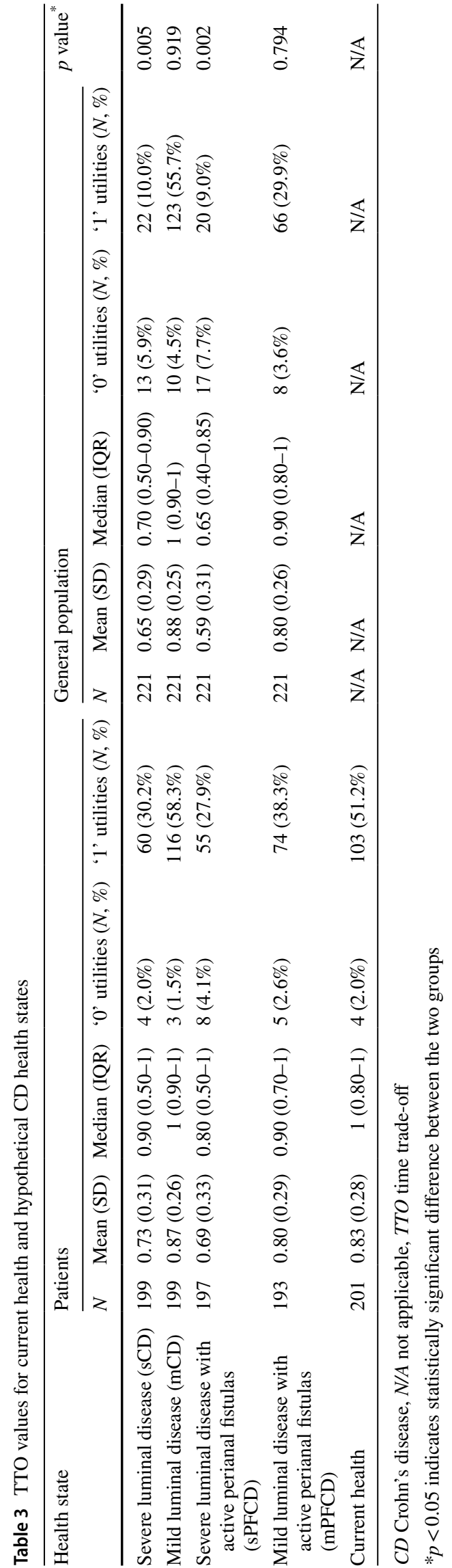

increase in subjective life expectancy $(p=0.018)$. People who had a family member or acquaintance diagnosed with CD valued health states higher $(+0.111, p=0.043)$, while disability pensioners rated them to be lower by 0.174 $(p=0.021)$.

\section{Discussion}

\section{Main findings}

This study evaluated individual preferences for different health states of CD using patients and a convenience sample from the Hungarian general population. The mean TTO values ranged between 0.69 and 0.88 derived from patients, and between 0.59 and 0.88 from the general population. In both groups, utilities for health states of severe and mild fistulising disease were significantly lower compared with health states describing the same luminal disease severity but with no concomitant perianal fistula symptoms. Patients assigned significantly higher values to the two health states of mild luminal severity than the general population, but this was not true for the severe health states. Patients with active perianal fistulas valued their current health much lower compared to those with inactive or no fistulas. Higher pain intensity experienced along with previous non-resection surgeries including perianal fistula surgery, strictureplasty and abscess drainage, were important predictors of reporting lower utilities for current health.

\section{Comparison with other studies}

Our results concur with findings from previous studies indicating that perianal fistulas have a considerable impact on HRQoL [5]. Similarly to our study, Longworth et al. [22] used a 10-year time frame to assess TTO utilities for perianal fistulising health states in the UK. In their study, patients and the general public valued SPFCD health state to a mean of 0.38 and 0.43 , while mPFCD resulted in a mean of 0.58 and 0.66 , respectively. In comparison, we found higher mean utilities for both SPFCD (patients: 0.69 and general public: 0.59 ) and mPFCD (both patients and general population: 0.80 ). The differences may be attributable to the different patient populations in terms of disease characteristics and severity as well as to the methodological variations of TTO between the two studies. For instance, the UK study [22] employed different health state vignettes and allowed to value health states worse than dead.

\section{Strengths and limitations}

This is the largest study involving patients to directly elicit utilities for CD health states. Furthermore, compared to 
Table 4 TTO utilities for current health in subgroups of patients $(n=201)$

\begin{tabular}{llrrr}
\hline Variables & Groups & $N$ & Mean (SD) & $p$ value \\
\hline Disease severity & Symptomatic remission (CDAI <150) & 153 & $0.85(0.27)$ & 0.086 \\
& Mild (CDAI 150-219) & 31 & $0.84(0.33)$ & \\
& Moderate to severe (CDAI 220 $\leq)$ & 17 & $0.69(0.34)$ & \\
Perianal fistulas & Inactive (PDAI $\leq 4)$ or no & 172 & $0.86(0.26)$ & 0.013 \\
& Active (PDAI $>4)$ & 29 & $0.67(0.37)$ & \\
Extraintestinal manifestations & No & 146 & $0.85(0.26)$ & 0.858 \\
& Yes & 55 & $0.82(0.29)$ & \\
Current treatment & Non-biological & 66 & $0.87(0.25)$ & 0.139 \\
& Biological & 132 & $0.81(0.30)$ & \\
Previous surgeries due to CD & None & 86 & $0.89(0.20)$ & 0.023 \\
& Resection & 31 & $0.87(0.26)$ & \\
& Non-resection & 51 & $0.76(0.33)$ & \\
& Both & 33 & $0.75(0.37)$ & \\
\hline
\end{tabular}

$C D$ Crohn's disease, CDAI Crohn's Disease Activity Index, PDAI Perianal Disease Activity Index, TTO time trade-off previous studies, health state vignettes used in the present study were more comprehensive featuring all aspects of HRQoL that may be relevant to CD patients. Another strength is the heterogeneous patient population recruited with regard to demographic as well as clinical characteristics, which satisfies the purpose of this valuation study. The study has limitations as well. First, two-thirds of the patients were treated with biological drugs and, as a result, they were in a relatively good health state. Second, there were differences in socio-demographic characteristics such as age and educational background between patients and the general population sample. Furthermore, our sample was on average younger, and had a higher proportion of male and highly educated participants compared to a nationally representative sample of the Hungarian general population (mean age 42 years, males $47 \%$, college/university graduates $21 \%$ ) [33].

\section{Practical implications}

The TTO seems to be superior to indirect utility assessment when it comes to PFCD. As shown by earlier studies, the EQ-5D-3L or EQ-5D-5L questionnaires could not distinguish between subgroups of $\mathrm{CD}$ patients based on perianal disease [6, 34]. We found that the 10-year TTO method discriminated well between HRQoL of patients with active and inactive or no perianal fistulas. In cost-effectiveness analyses of treatments for PFCD, directly elicited utilities can be recommended to be used to calculate QALYs. Before this study, in absence of relevant and reliable utility data specifically for PFCD, all published cost-effectiveness analyses of biological drugs relied on either luminal CD results or unpublished data such as expert opinion [35-37]. Our results fill in the gap in literature by providing robust health utilities from both patient and general population perspectives for the economic evaluations of biological drugs for CD.

In many countries including the US, Canada, the UK, the Netherlands and Hungary a general population perspective is recommended in the context of economic evaluations, while other countries, such as Sweden, recommend the patient perspective [38-42]. There is an increasing body of literature arguing that utilities based on both patient and general public preferences should be considered in health technology assessment [43-46]. A result with direct impact on cost-effectiveness studies of our study is that the differences in utilities between the two severe and mild states were found to be smaller for patients compared to those among members of the general population. This implies that using utilities reflecting patient preferences in cost-effectiveness analyses may reduce the QALY gain associated with therapy.

The assessment of HRQoL is advocated in guidelines for the management of PFCD by professional societies such as the European Crohn's and Colitis Organisation (ECCO) and the American College of Gastroenterology (ACG) [47-49]. However, currently there is no validated, disease-specific, patient-derived HRQoL tool for PFCD. Development of such an outcome measure, Crohn's Anal Fistula Quality of Life (CAF-QoL) is underway [50], although, the final version was not available at the time this manuscript was written. Importantly, we found that pain intensity has a large impact on HRQoL in patients with CD. Current ECCO and ACG guidelines recommend measuring abdominal pain as a part of the CDAI score. Our findings point out that thorough pain assessment would be essential in improving patients' HRQoL. 


\section{Conclusions}

Overall, the results of this study well reflect the severity of different health states of $\mathrm{CD}$, and highlight the additional HRQoL burden of living with perianal fistulising disease. It seems that the TTO method offers an accurate assessment of HRQoL in patients with PFCD, often not captured by health status questionnaires. Utilities from the present study are intended to support the optimization of treatment-related decision making in patients with luminal disease paralleled by active perianal fistulas and to establish a solid basis for cost-effectiveness analyses to compare treatment strategies.

Acknowledgements Open access funding provided by Corvinus University of Budapest (BCE). This research was supported by the Higher Education Institutional Excellence Program of the Ministry of Human Capacities in the framework of the 'Financial and Public Services' research project (20764-3/2018/FEKUTSTRAT) at Corvinus University of Budapest. Fanni Rencz is a postdoctoral research fellow at the Hungarian Academy of Sciences (MTA-BCE PPD 462025). The authors are grateful to Drs Zsuzsanna Kürti, Szilvia Lovas, Tamás Szamosi, Ferenc Zsigmond and Tamás Molnár for their contribution to the data collection. We also thank Tamás Cserni for the excellent research assistance.

\section{Compliance with ethical standards}

Conflict of interest The authors declare that they have no conflict of interest.

Research involving human participants All procedures performed in studies involving human participants were in accordance with the ethical standards of the institutional and/or national research committee and with the 1964 Helsinki Declaration and its later amendments or comparable ethical standards.

Informed consent Informed consent was obtained from all participants included in the study.

Open Access This article is distributed under the terms of the Creative Commons Attribution 4.0 International License (http://creativeco mmons.org/licenses/by/4.0/), which permits unrestricted use, distribution, and reproduction in any medium, provided you give appropriate credit to the original author(s) and the source, provide a link to the Creative Commons license, and indicate if changes were made.

\section{References}

1. Torres, J., Mehandru, S., Colombel, J.F., Peyrin-Biroulet, L.: Crohn's disease. Lancet 389(10080), 1741-1755 (2017). https:// doi.org/10.1016/s0140-6736(16)31711-1

2. Panes, J., Rimola, J.: Perianal fistulizing Crohn's disease: pathogenesis, diagnosis and therapy. Nat. Rev. Gastroenterol. Hepatol. 14(11), 652-664 (2017). https://doi.org/10.1038/nrgastro.2017.104

3. Mikocka-Walus, A., Knowles, S.R., Keefer, L., Graff, L.: Controversies revisited: a systematic review of the comorbidity of depression and anxiety with inflammatory bowel diseases. Inflamm.
Bowel Dis. 22(3), 752-762 (2016). https://doi.org/10.1097/ mib.0000000000000620

4. Neuendorf, R., Harding, A., Stello, N., Hanes, D., Wahbeh, H.: Depression and anxiety in patients with inflammatory bowel disease: a systematic review. J. Psychosom. Res. 87, 70-80 (2016). https://doi.org/10.1016/j.jpsychores.2016.06.001

5. Alrubaiy, L., Rikaby, I., Dodds, P., Hutchings, H.A., Williams, J.G.: Systematic review of health-related quality of life measures for inflammatory bowel disease. J. Crohns Colitis 9(3), 284-292 (2015). https://doi.org/10.1093/ecco-jcc/jjv002

6. Rencz, F., Lakatos, P.L., Gulacsi, L., Brodszky, V., Kurti, Z., Lovas, S., Banai, J., Herszenyi, L., Cserni, T., Molnar, T., Pentek, M., Palatka, K.: Validity of the EQ-5D-5L and EQ5D-3L in patients with Crohn's disease. Qual. Life Res. 28(1), 141-152 (2019). https://doi.org/10.1007/s11136-018-2003-4

7. Vollebregt, P.F., van Bodegraven, A.A., Markus-de Kwaadsteniet, T.M.L., van der Horst, D., Felt-Bersma, R.J.F.: Impacts of perianal disease and faecal incontinence on quality of life and employment in 1092 patients with inflammatory bowel disease. Aliment. Pharmacol. Ther. 47(9), 1253-1260 (2018). https:// doi.org/10.1111/apt.14599

8. Knowles, S.R., Graff, L.A., Wilding, H., Hewitt, C., Keefer, L., Mikocka-Walus, A.: Quality of life in inflammatory bowel disease: a systematic review and meta-analyses-part I. Inflamm. Bowel Dis. 24(4), 742-751 (2018). https://doi.org/10.1093/ibd/ izx 100

9. Knowles, S.R., Keefer, L., Wilding, H., Hewitt, C., Graff, L.A., Mikocka-Walus, A.: Quality of life in inflammatory bowel disease: a systematic review and meta-analyses-part II. Inflamm. Bowel Dis. 24(5), 966-976 (2018). https://doi.org/10.1093/ibd/izy015

10. van der Have, M., van der Aalst, K.S., Kaptein, A.A., Leenders, M., Siersema, P.D., Oldenburg, B., Fidder, H.H.: Determinants of health-related quality of life in Crohn's disease: a systematic review and meta-analysis. J. Crohns Colitis 8(2), 93-106 (2014). https://doi.org/10.1016/j.crohns.2013.04.007

11. Malinowski, K.P., Kawalec, P.: Health utility of patients with Crohn's disease and ulcerative colitis: a systematic review and meta-analysis. Expert Rev. Pharmacoecon. Outcomes Res. 16(4), 441-453 (2016). https://doi.org/10.1080/14737167.2016.1190644

12. Torrance, G.W.: Utility approach to measuring health-related quality of life. J. Chron. Dis. 40(6), 593-603 (1987)

13. Torrance, G.W.: Measurement of health state utilities for economic appraisal. J. Health Econ. 5(1), 1-30 (1986)

14. Rencz, F., Pentek, M., Bortlik, M., Zagorowicz, E., Hlavaty, T., Sliwczynski, A., Diculescu, M.M., Kupcinskas, L., Gecse, K.B., Gulacsi, L., Lakatos, P.L.: Biological therapy in inflammatory bowel diseases: access in Central and Eastern Europe. World J. Gastroenterol. 21(6), 1728-1737 (2015). https://doi.org/10.3748/ wjg.v21.i6.1728

15. Pentek, M., Lakatos, P.L., Oorsprong, T., Gulacsi, L., Pavlova, M., Groot, W., Rencz, F., Brodszky, V., Baji, P., Crohn's Disease Research, G: Access to biologicals in Crohn's disease in ten European countries. World J. Gastroenterol. 23(34), 6294-6305 (2017). https://doi.org/10.3748/wjg.v23.i34.6294

16. Gulacsi, L., Pentek, M., Rencz, F., Brodszky, V., Baji, P., Vegh, Z., Gecse, K.B., Danese, S., Peyrin-Biroulet, L., Lakatos, P.L.: Biosimilars for the management of inflammatory bowel diseases: economic considerations. Curr. Med. Chem. 2019;26(2):259-269 https://doi.org/10.2174/0929867324666170406112304

17. Rencz, F., Gulacsi, L., Pentek, M., Gecse, K.B., Dignass, A., Halfvarson, J., Gomollon, F., Baji, P., Peyrin-Biroulet, L., Lakatos, P.L., Brodszky, V.: Cost-utility of biological treatment sequences for luminal Crohn's disease in Europe. Expert Rev. Pharmacoecon. Outcomes Res. 17(6), 597-606 (2017). https:// doi.org/10.1080/14737167.2017.1322509 
18. Arseneau, K.O., Cohn, S.M., Cominelli, F., Connors Jr., A.F.: Cost-utility of initial medical management for Crohn's disease perianal fistulae. Gastroenterology 120(7), 1640-1656 (2001)

19. Gregor, J.C., McDonald, J.W., Klar, N., Wall, R., Atkinson, K., Lamba, B., Feagan, B.G.: An evaluation of utility measurement in Crohn's disease. Inflamm. Bowel Dis. 3(4), 265-276 (1997)

20. Tillinger, W., Mittermaier, C., Lochs, H., Moser, G.: Healthrelated quality of life in patients with Crohn's disease: influence of surgical operation-a prospective trial. Dig. Dis. Sci. 44(5), 932-938 (1999)

21. Mahadev, S., Young, J.M., Selby, W., Solomon, M.J.: Selfreported depressive symptoms and suicidal feelings in perianal Crohn's disease. Colorect. Dis. 14(3), 331-335 (2012). https:// doi.org/10.1111/j.1463-1318.2011.02613.x

22. Longworth, L., Fountain, D., Singh, J., Azzabi, I., Owen, G., Lundstam, U., Sebastian, S.: Elicitation of health-related utility in perianal fistula in Crohn's disease. Patient (2018). https://doi. org/10.1007/s40271-018-0352-2. (Epub ahead of print)

23. Winship, D.H., Summers, R.W., Singleton, J.W., Best, W.R., Becktel, J.M., Lenk, L.F., Kern Jr., F.: National Cooperative Crohn's Disease Study: study design and conduct of the study. Gastroenterology 77(4 Pt 2), 829-842 (1979)

24. Irvine, E.J.: Usual therapy improves perianal Crohn's disease as measured by a new disease activity index. McMaster IBD Study Group. J. Clin. Gastroenterol. 20(1), 27-32 (1995)

25. Losco, A., Vigano, C., Conte, D., Cesana, B.M., Basilisco, G.: Assessing the activity of perianal Crohn's disease: comparison of clinical indices and computer-assisted anal ultrasound. Inflamm. Bowel Dis. 15(5), 742-749 (2009). https://doi. org/10.1002/ibd.20826

26. Schunemann, H.J., Stahl, E., Austin, P., Akl, E., Armstrong, D., Guyatt, G.H.: A comparison of narrative and table formats for presenting hypothetical health states to patients with gastrointestinal or pulmonary disease. Med. Decis. Making 24(1), 53-60 (2004). https://doi.org/10.1177/0272989x03261566

27. Arnesen, T., Trommald, M.: Are QALYs based on time tradeoff comparable? - a systematic review of TTO methodologies. Health Econ. 14(1), 39-53 (2005). https://doi.org/10.1002/ hec. 895

28. Oppe, M., Devlin, N.J., van Hout, B., Krabbe, P.F., de Charro, F.: A program of methodological research to arrive at the new international EQ-5D-5L valuation protocol. Value Health 17(4), 445-453 (2014). https://doi.org/10.1016/j.jval.2014.04.002

29. Poor, A.K., Brodszky, V., Pentek, M., Gulacsi, L., Ruzsa, G., Hidvegi, B., Hollo, P., Karpati, S., Sardy, M., Rencz, F.: Is the DLQI appropriate for medical decision-making in psoriasis patients? Arch. Dermatol. Res. 310(1), 47-55 (2018). https:// doi.org/10.1007/s00403-017-1794-4

30. Rencz, F., Baji, P., Gulacsi, L., Karpati, S., Pentek, M., Poor, A.K., Brodszky, V.: Discrepancies between the Dermatology Life Quality Index and utility scores. Qual. Life Res. 25(7), 1687-1696 (2016). https://doi.org/10.1007/s11136-015-1208-Z

31. Rencz, F., Brodszky, V., Stalmeier, P.F., Tamasi, B., Karpati, S., Pentek, M., Baji, P., Mitev, A.Z., Gulacsi, L.: Valuation of pemphigus vulgaris and pemphigus foliaceus health states: a convenience sample experiment. Br. J. Dermatol. 175(3), 593599 (2016). https://doi.org/10.1111/bjd.14647

32. Rencz, F., Pentek, M., Stalmeier, P.F.M., Brodszky, V., Ruzsa, G., Gradvohl, E., Baji, P., Gulacsi, L.: Bleeding out the qualityadjusted life years: evaluating the burden of primary dysmenorrhea using time trade-off and willingness-to-pay methods. Pain 158(11), 2259-2267 (2017). https://doi.org/10.1097/j. pain.0000000000001028

33. Hungarian Central Statistical Office, Microcensus 2016. ISBN 978-963-235-494-10̈. http://www.ksh.hu/docs/eng/xftp/idosz aki/microcensus2016/microcensus_2016_3.pdf. Accessed 24 Feb 2019

34. Casellas, F., Vivancos, J.L., Sampedro, M., Malagelada, J.R.: Relevance of the phenotypic characteristics of Crohn's disease in patient perception of health-related quality of life. Am. J. Gastroenterol. 100(12), 2737-2742 (2005). https://doi.org/10. 1111/j.1572-0241.2005.00360.x

35. Baji, P., Gulácsi, L., Brodszky, V., Végh, Z., Danese, S., Irving, P.M., Peyrin-Biroulet, L., Schreiber, S., Rencz, F., Péntek, M.: Cost-effectiveness of biological treatment sequences for fistulising Crohn's disease across Europe. United Eur. Gastroenterol. J. 6(2), 310-321 (2018). https://doi.org/10.1177/2050640617 708952

36. Clark, W., Raftery, J., Song, F., Barton, P., Cummins, C., FrySmith, A., Burls, A.: Systematic review and economic evaluation of the effectiveness of infliximab for the treatment of Crohn's disease. Health Technol. Assess. 7(3), 1-67 (2003)

37. Lindsay, J., Punekar, Y.S., Morris, J., Chung-Faye, G.: Healtheconomic analysis: cost-effectiveness of scheduled maintenance treatment with infliximab for Crohn's disease-modelling outcomes in active luminal and fistulizing disease in adults. Aliment. Pharmacol. Ther. 28(1), 76-87 (2008). https://doi.org/10 $.1111 / \mathrm{j} .1365-2036.2008 .03709 . x$

38. Canadian Agency for Drugs and Technologies in Health. Guidelines for the Economic Evaluation of Health Technologies. https ://www.cadth.ca/media/pdf/186_EconomicGuidelines_e.pdf (2006). Accessed $20 \mathrm{Feb} 2019$

39. National Institute for Health and Care Excellence (NICE). Guide to the Methods of Technology Appraisal. https://www.nice.org. uk/guidance/pmg9/resources/guide-to-the-methods-of-techn ology-appraisal-2013-pdf-2007975843781 (2013). Accessed 20 Feb 2019

40. Nederland, Zorginstituut: Richtlijn voor het uitvoeren van economische evaluaties in de gezondheidszorg. Zorginstituut Nederland, Diemen (2016)

41. EUnetHTA Methods for health economic evaluations-a guideline based on current practices in Europe. https://www.eunet hta.eu/wp-content/uploads/2018/03/Methods_for_health_econo mic_evaluations.pdf (2015). Accessed 11 Dec 2018

42. Boncz, I., Sebestyen, A.: Financial deficits in the health services of the UK and Hungary. Lancet 368(9539), 917-918 (2006). https://doi.org/10.1016/s0140-6736(06)69369-0

43. Versteegh, M.M., Brouwer, W.B.F.: Patient and general public preferences for health states: a call to reconsider current guidelines. Soc. Sci. Med. 1982(165), 66-74 (2016). https:// doi.org/10.1016/j.socscimed.2016.07.043

44. Mott, D.J.: Incorporating quantitative patient preference data into healthcare decision making processes: is HTA falling behind? Patient 11(3), 249-252 (2018). https://doi.org/10.1007/ s40271-018-0305-9

45. Wale, J., Scott, A.M., Hofmann, B., Garner, S., Low, E., Sansom, L.: Why patients should be involved in health technology assessment. Int. J. Technol. Assess. Health Care 33(1), 1-4 (2017). https://doi.org/10.1017/s0266462317000241

46. Muhlbacher, A.C.: Patient-centric HTA: different strokes for different folks. Expert Rev. Pharmacoecon. Outcomes Res. 15(4), 591-597 (2015). https://doi.org/10.1586/14737167.2015.10382 45

47. Sahnan, K., Tozer, P.J., Adegbola, S.O., Lee, M.J., Heywood, N., McNair, A.G.K., Hind, D., Yassin, N., Lobo, A.J., Brown, S.R., Sebastian, S., Phillips, R.K.S., Lung, P.F.C., Faiz, O.D., Crook, K., Blackwell, S., Verjee, A., Hart, A.L., Fearnhead, N.S.: Developing a core outcome set for fistulising perianal Crohn's disease. Gut 68(2), 226-238 (2019). https://doi. org/10.1136/gutjnl-2017-315503 
48. Gecse, K.B., Sebastian, S., Hertogh, G., Yassin, N.A., Kotze, P.G., Reinisch, W., Spinelli, A., Koutroubakis, I.E., Katsanos, K.H., Hart, A., van den Brink, G.R., Rogler, G., Bemelman, W.A.: Results of the fifth scientific workshop of the ECCO [II]: clinical aspects of perianal fistulising Crohn's disease-the unmet needs. J Crohns Colitis 10(7), 758-765 (2016). https:// doi.org/10.1093/ecco-jcc/jjw039

49. Lichtenstein, G.R., Loftus, E.V., Isaacs, K.L., Regueiro, M.D., Gerson, L.B., Sands, B.E.: ACG clinical guideline: management of Crohn's disease in adults. Am. J. Gastroenterol. 113(4), 481-517 (2018). https://doi.org/10.1038/ajg.2018.27
50. Adegbola, S., Dibley, L., Sahnan, K., Tozer, P., Yassin, N., Wade, T., Verjee, A., Sawyer, R., Mannick, S., Lung, P.: N001 Developing a quality of life score for Crohn's anal fistula (CAFQoL). J. Crohn's Colitis 12(1), S568 (2018)

Publisher's Note Springer Nature remains neutral with regard to jurisdictional claims in published maps and institutional affiliations.

\section{Affiliations}

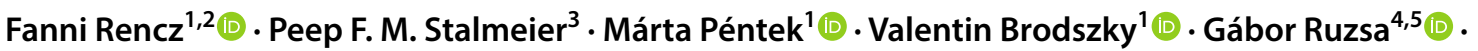

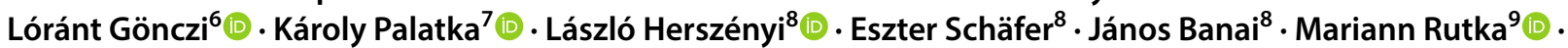 László Gulácsi ${ }^{1}$ (1) Peter L. Lakatos ${ }^{6,10}$ (}

1 Department of Health Economics, Corvinus University of Budapest, Fơvám tér 8, 1093 Budapest, Hungary

2 Premium Postdoctoral Research Program, Hungarian Academy of Sciences, Nádor u. 7, 1051 Budapest, Hungary

3 Radboud University Medical Centre, PO Box 9101, 6500 HB Nijmegen, The Netherlands

4 Doctoral School of Psychology, Institute of Psychology, Eötvös Loránd University of Sciences, Izabella u. 46, 1064 Budapest, Hungary

5 Department of Statistics, Corvinus University of Budapest, Fővám tér 8, 1093 Budapest, Hungary

6 1st Department of Medicine, Semmelweis University, Korányi Sándor u. 2/a, 1083 Budapest, Hungary
7 Division of Gastroenterology, Department of Internal Medicine, University of Debrecen, Nagyerdei krt. 98, 4032 Debrecen, Hungary

8 Medical Centre, Hungarian Defence Forces, Podmaniczky u. 109-111, 1062 Budapest, Hungary

9 1st Department of Internal Medicine, University of Szeged, Korányi fasor 8-10, 6720 Szeged, Hungary

10 Division of Gastroenterology, McGill University, MUHC, Montreal General Hospital, 1650 Ave. Cedar, D16.173.1, Montreal, QC H3G 1A4, Canada 